\title{
Transthoracic echocardiography in the diagnosis of type A dissecting aortic aneurysm
}

\section{Alma Sijamija*1, Nermir Granov², Nedžad Hadžić', Omer Perva², Alma Agačevićr}

'Travnik General Hospital, Travnik, Bosnia and Herzegovina

${ }^{2}$ Clinical Center University of Sarajevo, Sarajevo, Bosnia and Herzegovina
RECEIVED:

September 22, 2016

ACCEPTED:

October 10, 2016

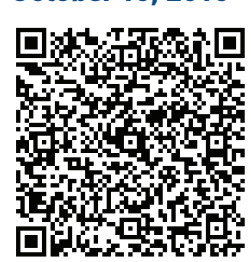

KEYWORDS: echocardiography, aortic dissection, survival.

CITATION: Cardiol Croat. 2016;11(10-11):487. | DOI: http://dx.doi.org/10.15836/ccar2016.487

*ADDRESS FOR CORRESPONDENCE: Alma Sijamija, Travnik General Hospital, Kalibunar bb, 72270 Travnik, Bosnia and Herzegovina. / Phone: +387-61-780-085 / E-mail: alma.sijamija@hotmail.com

ORCID: Alma Sijamija, http://orcid.org/0000-0003-2818-0501 • Nermir Granov, http://orcid.org/0000-0002-6228-6230 Nedžad Hadžić, http://orcid.org/0000-0002-7186-7803 • Omer Perva, http://orcid.org/0000-0003-2645-1558 Alma Agačević, http://orcid.org/0000-0003-4671-0991

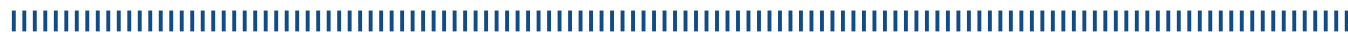
Introduction: Aortic dissection (AD) is defined as disruption of the medial layer provoked by intramural bleeding, resulting in separation of the aortic wall layers and subsequent formation of a true lumen and a false lumen with or without communication It occurs at an estimated rate of 3 per 100,000 people every year, among them 40\% die immediately and do not reach a hospital in time. Magnetic resonance imaging is currently the gold standard for the detection and assessment of AD, with a sensitivity and a specificity of $98 \%$, however it has limited availability. Transthoracic echocardiography (TTE) is more commonly available diagnostic tool and has sensitivity of up to $98 \%$ and a specificity of up to $97 \%{ }^{1.3}$ Aim: To highlight the importance of TTE in the diagnosis of type A dissecting aortic aneurysm.

Case 1: 67-year-old male was admitted to Internal department due to chest pain and dyspnea. Physical examination showed unmeasurable arterial blood pressure on the right arm and 140/100 $\mathrm{mmHg}$ on the left; diastolic murmur over precordium. ECG: downsloping ST segment depression in V4-6. Troponin T test was positive. TTE revealed dilated ascending aorta $(56 \mathrm{~mm})$ with signs of acute dissection: prolapse of intimal flap into the LVOT and severe AR +4 (Figure 1). CT angiography confirmed aneurysm of the ascending aorta starting from the root of LCA and was tracked over the entire aorta to the AIC. Bentall procedure was performed.

Case 2: 50-year-old male was presented to the internist due to occasional chest pain and shortness of breath, appeared 3 months earlier. Physical examination revealed hypertension, diastolic murmur over precordium. TTE: dilated ascending aorta (48 mm), structure above projection of non-coronary aortic cusp, at the level of sinotubular junction, reminiscent of the intimal flap; severe $M R+4$ and $A R+3 / 4$ (Figure 2). CT angiography visualized the hypodensic linear area that separates lumen of thoracic aorta into two parts and extends to the bases of brachiocephalic trunk. Patient received surgical treatment.

On regular follow-up, 5 years after the procedures both patients feel great

Conclusion: Echocardiography has become the preferred imaging modality for suspected aortic dissection. Prompt diagnosis and access to surgical therapy increases survival.

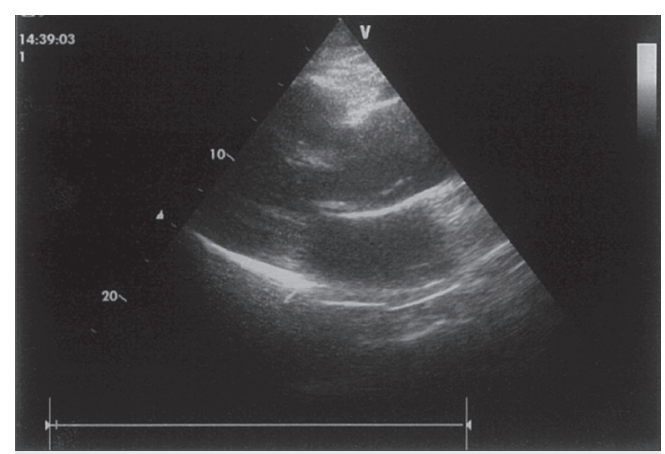

A transthoracic echocardiogram revealed dilated ascending aorta $(56 \mathrm{~mm})$ with signs of acute dissection: prolapse of intimal flap into the left ventricular outflow tract.

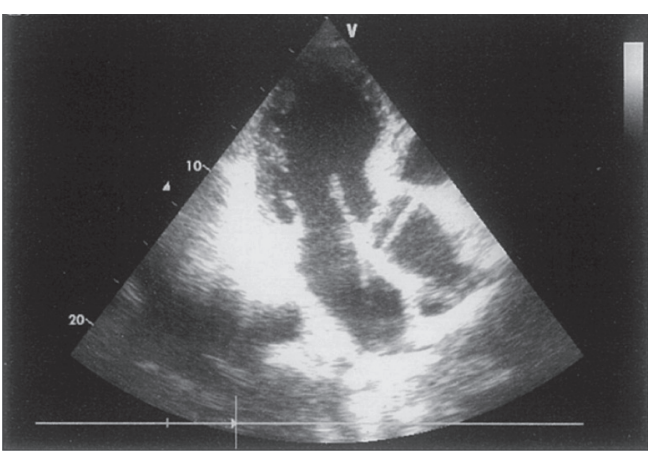

A transthoracic echocardiogram: dilated ascending aorta $(48 \mathrm{~mm})$, structure above projection of non-coronary aortic cusp, at the level of sinotubular junction, reminiscent of the intimal flap.

\section{FIGURE 2.}

LITERATURE IIIIIIIIIIIIIIIIIIIIIIIIIIIIIIIIIIIIIIIIIIIIIIIIIIIIIIIIIIIIIIIIIIIIIIIIIIIIIIIIIIIIIIIIIIIIIIIIIIIIIIII

1. Bossone E, Suzuki T, Eagle KA, Weinsaft JW. Diagnosis of acute aortic syndromes: imaging and beyond. Herz. 2013;38(3):269-76. DOI: http://dx.doi.org/10.1007/s00059-012-3710-1

2. Sheikh AS, Ali K, Mazhar S. Acute aortic syndrome. Circulation. 2013;128(10):1122-7. DOI: http://dx.doi.org/10.1161/CIRCULATIONAHA.112.000170

3. Daily PO, Trueblood HW, Stinson EB, Wuerflein RD, Shumway NE. Management of acute aortic dissections. Ann Thorac Surg. 1970;10(3):237-47. DOI: http://dx.doi.org/10.1016/S0003-4975(10)65594-4 